\title{
THE ARTERIAL BLOOD GASES, THE OXYGEN DISSOCIATION CURVE, AND THE ACID-BASE BALANCE IN POLYCYTHEMIA VERA ${ }^{1}$
}

\author{
By DONALD E. CASSELS AND MINERVA MORSE
}

(From the Department of Pediatrics, University of Chicago Clinics, Chicago, Ill.)

(Submitted for publication May 26, 1952; accepted October 22, 1952)

Studies of the circulation and pulmonary function in normal children and in patients with polycythemia related to cyanosis in congenital heart disease raised questions concerning the extent to which polycythemia itself might be responsible for some of the abnormalities observed in the blood in cyanotic congenital heart disease. These questions concerned the possibility that the increased viscosity of polycythemic blood might prevent proper diffusion of oxygen in the alveolarcapillary system, resulting in arterial oxygen unsaturation, the characteristics of the oxyhemoglobin dissociation curve in polycythemia vera, since this has been found shifted to the right in the blood of patients with cyanotic congenital heart disease (1), and the relation of a low $\mathrm{CO}_{2}$ content and combining power to polycythemia, since these were observed to be low in the secondary polycythemia of congenital heart disease (2-4).

Studies of the blood in polycythemia vera were made and compared with similar studies in cyanotic congenital heart disease. These included determinations of the oxygen content, oxygen capacity and oxygen saturation of arterial blood, the effect of breathing oxygen on the oxygen content of such blood, the oxyhemoglobin dissociation curve and the carbon dioxide content, combining power and tension, and the $\mathrm{pH}_{\mathbf{s}}$ of arterial blood. It was hoped that some of these might be sufficiently characteristic to be helpful in differentiating primary from secondary polycythemia. This report presents the data obtained during these studies.

\section{MATERIAL}

Blood from patients considered to have polycythemia vera was made available by the Department of Hema-

\footnotetext{
1 Supported by a grant from the Douglas Smith Foundation for Medical Research at the University of Chicago.
}

tology. In each case the patient rested one-half hour before the arterial sample was drawn. The patients varied in age from 14 to 62 years. For purposes of comparison the arterial blood from a group of 9 medical students was investigated in the same manner.

\section{METHODS}

Samples of arterial blood were collected in a syringe containing mineral oil to fill the dead space of the syringe. The blood was transferred immediately to a sampling tube containing mercury and a small amount of heparin, the tube was sealed with mercury, rotated to mix the blood with heparin, and stored in ice water in a refrigerator until the analyses were completed.

For the determination of oxygen capacity and carbon dioxide combining power, 4 to $5 \mathrm{ml}$. samples were equilibrated at $37^{\circ}$ in a tonometer, of approximately $225 \mathrm{ml}$. capacity, which contained carbon dioxide and oxygen at approximate tensions of $40 \mathrm{~mm}$. and $185 \mathrm{~mm}$., respectively. The oxygen and carbon dioxide contents of both the samples as drawn and those equilibrated in the tonometers were determined by the manometric method of Van Slyke and Neill (5). From these data and the gas contents of the tonometers, determined by Haldane analysis, the percentage of oxygen saturation, carbon dioxide combining power $\left(T_{40}\right)$ of the blood and plasma, the carbon

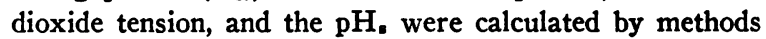
described by Dill and his coworkers (6).

The in vitro tonometer method was employed for the determination of the oxygen dissociation curve, essentially as described by Dill in the study of Keys, Hall, and Barron (7). Further details are given in an earlier report (8).

Oxygen for breathing was supplied from a Douglas bag through a modified Henderson-Haggard valve (9) and an anesthesia mask. An arterial sample was drawn just before oxygen breathing began and after it had continued for 5 minutes.

\section{RESULTS}

Table $\mathrm{I}^{3}$ gives the results of analyses of samples of arterial blood from 17 patients with poly-

2 Through the courtesy and cooperation of Dr. Leon Jacobson, Dr. Matthew Block and others in the department.

3 The patients studied had polycythemia of unknown origin, without demonstrable cardiac or pulmonary disease, 
cythemia vera and from 9 young adult males who were in good health. Since the same methods were employed by Dill, Edwards and Consolazio (10) in a study of 12 normal adult males, the mean values and the range of variation observed in

with one exception. Of the three with low arterial oxygen saturation, at autopsy J. P. revealed no congenital cardiac defects or primary pulmonary disease. M. H. had no cardiac enlargement and had clear lung fields, although he had a slow auricular fibrillation thought to be arteriosclerotic in origin. Persistent polycythemia, controlled with nitrogen mustard and $\mathrm{P}^{\$ 8}$, hyperplastic bone marrow, and leucocytosis varying from 8,000 to 17,000 before therapy were considered diagnostic of a primary polycythemia and this diagnosis was never questioned. J. D., whose polycythemia is controlled by repeated phlebotomy, showed no change in blood gases after a four year interval. She had, however, thoracolumbar scoliosis, maximal at $\mathrm{T} 12$, and occasional episodes of pulmonary their study have been included in the table for reference. Aside from slightly higher values for oxyhemoglobin capacity in our group of normal males and the resultant effect of the increased ratio of red cells to plasma on the carbon dioxide

hemorrhage during periods of marked polycythemia. Polycythemia and cyanosis had been apparent when first seen in 1939, when the lung fields were clear. Pulmonary function studies in 1952 are probably complicated by residual effects of hemorrhage. The lung volumes were: inspiratory capacity $1,275 \mathrm{cc}$, expiratory reserve $577 \mathrm{cc}$., residual volume 1,004 cc., or a total capacity of 2,856 and vital capacity of 1,852 . The inspiratory capacity is low. The alveolar-arterial gradients were greatly increased, the $\mathrm{pCO}_{2}$ gradient being $16.4 \mathrm{~mm}$. and the $\mathrm{pO}_{2}$ gradient 66.5 $\mathrm{mm}$. The early diagnosis was polycythemia vera with concurrent scoliosis, and she was treated with phenylhydrazine, $x$-ray therapy, and for the past few years with repeated phlebotomy.

Table I

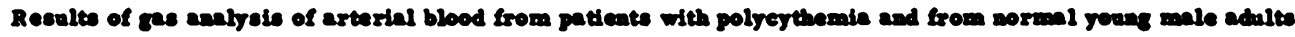

\begin{tabular}{|c|c|c|c|c|c|c|c|c|c|}
\hline Subject & Age & $\operatorname{sex}$ & $\begin{array}{l}\text { Oxybamoglobia } \\
\text { capacity }\end{array}$ & $\begin{array}{l}\text { Oxybemoglobin } \\
\text { content }\end{array}$ & $\begin{array}{l}\text { Percentage } \\
\text { enturation }\end{array}$ & $\begin{array}{c}\mathrm{I}_{40} \\
\mathrm{CO}_{2}\end{array}$ & $\underset{240}{P l a m e} \mathrm{CO}_{2}$ & $\mathrm{CO}_{2}$ Tensten & pla \\
\hline
\end{tabular}

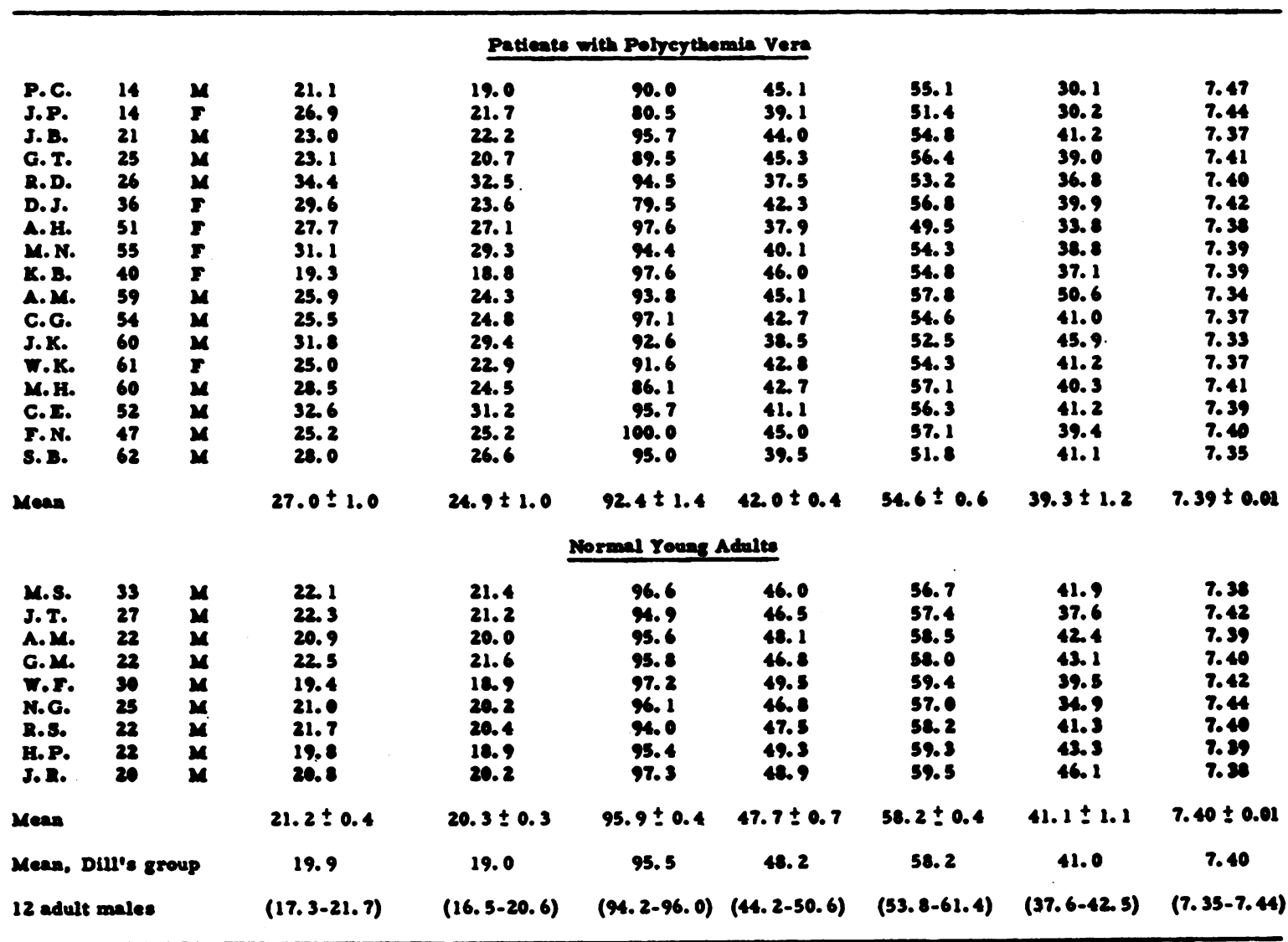


content of the blood, the results of the two studies on normal males are very similar.

Arterial saturations in normal adults were found in the present study to vary from 94.0 to 97.5 per cent, with a mean of 95.9 per cent. The lower limit of arterial saturation as determined by the tonometer method appears to be near 94 per cent. These values are lower than the mean value of 97.9 per cent saturation which Wood (11) found for 46 arterial samples from normal subjects when he employed the method described by Roughton, Darling, and Root (12). Roughton has shown that there is a systematic error of approximately 2 per cent when the tonometer method is used for determining oxygen capacity. If a correction of 2 per cent is subtracted from the oxyhemoglobin capacities of the present data, a mean arterial saturation of 97.9 per cent is obtained for the normal adult males. Since the tonometer method has shown such good agreement in the results of two laboratories, confidence can be placed in the comparison of results from the normal group with those from patients with polycythemia vera, regardless of whether the absolute value is correct.

In the patients with polycythemia vera, eight patients were found to have arterial saturations less than 94 per cent, and four of these had saturations less than 90 per cent. One of the patients with a low saturation, case 2 , died of an intercurrent infection, a brain abscess, 3 years subsequent to the determinations. No cardiac or pulmonary pathology was identified on autopsy and the diagnosis of polycythemia vera was confirmed.

Five patients were studied before and after re- duction of polycythemia by therapy. The results of analysis of arterial blood from these patients are given in Table II. It is evident that the arterial saturation shows no consistent response. In one patient with an initial oxygen capacity of 30 vollumes per cent and arterial saturation of 79 per cent, practically no change occurred when the oxygen capacity was reduced to 24 volumes per cent. In another patient arterial saturation was initially high and remained high when the oxygen capacity was reduced from 28 to 21 volumes per cent. In two cases low initial arterial saturations of 89 and 86 per cent were raised to 98 and 94 per cent, respectively, after polycythemia had been reduced; but in another instance a saturation of 94 per cent was reduced to 89 per cent when the oxygen capacity was reduced from 31 to 21 volumes per cent. The variation in response of the arterial saturation to reduction of the polycythemia is confusing. It suggests that factors other than polycythemia itself are concerned in the maintenance of arterial saturation.

In the hope of obtaining information concerning the cause of arterial unsaturation observed in an occasional patient with polycythemia vera, the effect of breathing 99.6 per cent oxygen upon the arterial saturation was tested in 9 patients. In this group arterial saturation while breathing air ranged from 76.9 to 97.1 per cent. This group included four patieints with saturations below the normal range. Table III gives the results both of the patients with polycythemia vera and a group of healthy young adult males. A greater increase in oxygen content due to oxygen breathing is found in the polycythemic group. It is related

Table II

Iffects of reduction therapy upon the oxpgen saturation and the acid-bese cquilibrium of the bleod in patients with polyerthemin rera

\begin{tabular}{|c|c|c|c|c|c|c|c|c|c|c|c|c|c|c|c|c|}
\hline \multirow{3}{*}{$\begin{array}{l}\text { Subject } \\
\text { M. N. }\end{array}$} & \multirow{3}{*}{$\frac{\text { Age }}{55}$} & \multirow{3}{*}{$\frac{\operatorname{sex}}{\mathrm{F}}$} & \multirow{2}{*}{\multicolumn{2}{|c|}{$\begin{array}{l}\text { Oxylemoglobin } \\
\text { capacity } \\
\text { Before After }\end{array}$}} & \multirow{2}{*}{\multicolumn{2}{|c|}{$\begin{array}{l}\text { Oxy herwoglobil } \\
\text { content } \\
\text { Before After }\end{array}$}} & \multirow{2}{*}{\multicolumn{2}{|c|}{$\begin{array}{l}\text { Percentage } \\
\text { enturation } \\
\text { Before After }\end{array}$}} & \multirow{2}{*}{\multicolumn{2}{|c|}{$\begin{array}{c}\text { Blood } \mathrm{CO}_{2} \\
\mathrm{~T}_{40} \\
\text { Before After }\end{array}$}} & \multirow{2}{*}{\multicolumn{2}{|c|}{$\begin{array}{l}\text { Plaema } \mathrm{CO}_{2} \\
\mathrm{~T}_{40} \\
\text { Before After }\end{array}$}} & \multicolumn{2}{|c|}{$\mathrm{CO}_{2}$ Tension } & \multicolumn{2}{|c|}{$\mathrm{PH}_{\mathbf{s}}$} \\
\hline & & & & & & & & & & & & & Before & After & Befere & After \\
\hline & & & 31.1 & 21.1 & 29.3 & 18.9 & 94.4 & 89.4 & 40.1 & 46.9 & 54.3 & 57.3 & 38.8 & 40.4 & 7.39 & 7.40 \\
\hline D.J. & 36 & $\mathbf{F}$ & 29.6 & 24.4 & 23.6 & 18.6 & 79.5 & 77.7 & 42.3 & 43.6 & 56.8 & 54.7 & 39.9 & 46.2 & 7.42 & 7.35 \\
\hline A.H. & 51 & $\mathbf{F}$ & 27.7 & 21.5 & 27.1 & 20.8 & 97.6 & 96.8 & 37.9 & 44.4 & 49.5 & 54.6 & 33.8 & 40.0 & 7.38 & 7.38 \\
\hline G. $\boldsymbol{T}$. & 25 & $\mathbf{M}$ & 23.1 & 21.9 & 20.7 & 21.5 & 89.5 & 98.0 & 45.3 & 4.7 & 56.4 & 55.0 & 39.0 & 35.7 & 7.41 & 7.42 \\
\hline M. K. & 60 & $\mathbf{M}$ & 28.5 & 21.6 & 24.6 & 20.2 & 86.1 & 93.6 & 42.7 & 47.9 & 57.1 & 58.7 & 40.3 & 37.6 & 7.41 & 7.43 \\
\hline
\end{tabular}


STUDIES IN POLYCYTHEMIA VERA

Table III

Effect of breathing oxygen on the oxygen content of arterial blood in patients with polycythemia vera and in normal young adults

\begin{tabular}{clccc}
\hline Subject & $\begin{array}{l}\text { Arterial } \\
\text { saturation, } \\
\text { breathing } \\
\text { air }\end{array}$ & $\begin{array}{c}\text { Oxygen Content of the Blood } \\
\text { air }\end{array}$ & $\begin{array}{c}\text { Oxybemoglobin } \\
\text { capacity }\end{array}$ & $\begin{array}{c}\text { Physically } \\
\text { dissolved } \\
\text { oxygen }\end{array}$ \\
oxygen
\end{tabular}

\begin{tabular}{|c|c|c|c|c|c|c|}
\hline \multirow[b]{2}{*}{$\begin{array}{l}\text { P. C. } \\
\text { M.N. } \\
\text { R. D. } \\
\text { W. K. } \\
\text { S. B. } \\
\text { J. B. } \\
\text { A. M. } \\
\text { C. G. } \\
\text { D. J. }\end{array}$} & \multirow[b]{2}{*}{$\begin{array}{l}90.0 \\
89.4 \\
94.5 \\
91.6 \\
95.0 \\
95.7 \\
93.8 \\
97.1 \\
76.9\end{array}$} & \multicolumn{4}{|c|}{ Patients with Polycythemia Vera } & \multirow[b]{2}{*}{$\begin{array}{l}0.52 \\
0.28 \\
1.54 \\
1.43 \\
1.08 \\
1.42 \\
1.41 \\
1.43 \\
0.77\end{array}$} \\
\hline & & $\begin{array}{l}19.22 \\
19.08 \\
32.67 \\
23.14 \\
26.78 \\
22.22 \\
24.48 \\
24.95 \\
15.79\end{array}$ & $\begin{array}{l}21.61 \\
21.41 \\
35.93 \\
26.47 \\
29.06 \\
24.43 \\
27.47 \\
26.92 \\
21.07\end{array}$ & $\begin{array}{l}2.39 \\
2.33 \\
3.26 \\
3.33 \\
2.28 \\
2.21 \\
2.99 \\
1.97 \\
5.28\end{array}$ & $\begin{array}{l}21.09 \\
21.13 \\
34.39 \\
25.04 \\
27.98 \\
23.01 \\
25.89 \\
25.49 \\
20.30\end{array}$ & \\
\hline \multicolumn{7}{|c|}{ Normal Young Adults } \\
\hline $\begin{array}{l}\text { M.S. } \\
\text { J.T. } \\
\text { A. M. } \\
\text { G. M. } \\
\text { W. F. } \\
\text { N.G. } \\
\text { R.S. } \\
\text { H.P. } \\
\text { J.R. }\end{array}$ & $\begin{array}{l}96.6 \\
94.9 \\
95.6 \\
95.8 \\
97.2 \\
96.1 \\
94.0 \\
95.4 \\
97.3\end{array}$ & $\begin{array}{l}21.56 \\
21.39 \\
20.15 \\
21.53 \\
19.09 \\
20.39 \\
20.55 \\
19.05 \\
20.42\end{array}$ & $\begin{array}{l}22.98 \\
23.55 \\
21.94 \\
23.79 \\
20.58 \\
21.47 \\
22.33 \\
20.96 \\
21.70\end{array}$ & $\begin{array}{l}1.42 \\
2.16 \\
1.79 \\
2.26 \\
1.49 \\
1.08 \\
1.78 \\
1.91 \\
1.28\end{array}$ & $\begin{array}{l}22.13 \\
22.34 \\
20.89 \\
22.75 \\
19.44 \\
21.03 \\
21.66 \\
19.77 \\
20.79\end{array}$ & $\begin{array}{l}0.85 \\
1.21 \\
1.05 \\
1.04 \\
1.14 \\
0.44 \\
0.67 \\
1.19 \\
0.91\end{array}$ \\
\hline
\end{tabular}

to their lower mean arterial saturation and their higher oxygen capacity. In both groups physically dissolved oxygen as measured by the oxygen content in excess of the hemoglobin capacity is in every instance lower than the theoretical amount, which is approximately $2 \mathrm{ml}$. per $100 \mathrm{ml}$. This is calculated from the solubility coefficient of oxygen in blood as given by Sendroy, Dillon, and Van Slyke (13) and the alveolar oxygen tension. The discrepancy may be due to any number of factors described by Wood (11) with the additional possibility that some of the dissolved oxygen, held in solution by the high oxygen pressure, may be lost by reduction in pressure during the handling involved in transferring the blood from the syringe to the sampling tube and thence into the measuring pipette. Since the methods employed were the same for both the normal group and the patients with polycythemia vera, the finding of comparable values for physically dissolved oxygen in the two groups may be explained by the observation of Sendroy and his co-workers (13) that the solubility coefficient of oxygen in blood increases with increasing hemoglobin capacity.

To determine whether the hemoglobin of polycythemic blood differs from normal blood in its affinity for oxygen, the oxyhemoglobin dissociation curve of the blood was determined for $8 \mathrm{pa}-$ tients with polycythemia vera. The results are shown in Figure 1 as percentage saturation plotted against corresponding tensions, for oxygen tensions of $30,40,50,60,70$, and $80 \mathrm{~mm}$. The solid line of the chart represents the oxyhemoglobin dissociation curve for normal adults which was determined in our laboratory by the same methods (8). The area within the broken lines represents the range of variation for normal adults as defined by plus or minus 2 standard deviations from the mean. There is no evidence that the oxygen dissociation curve of the blood from patients with 


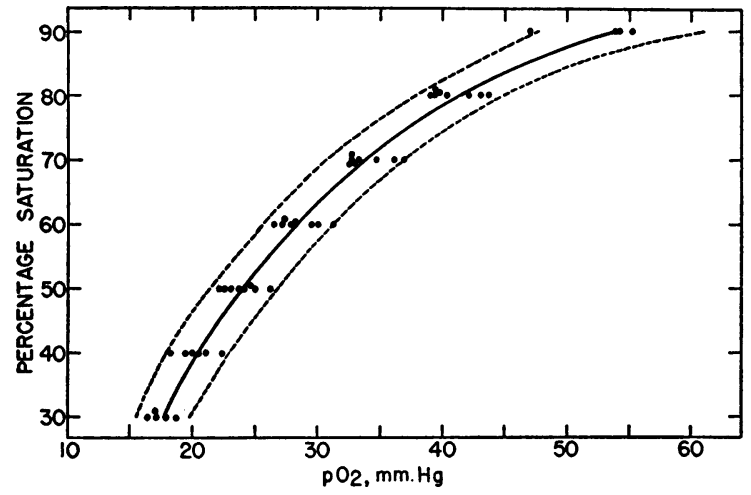

Fig. 1. Relation Between Oxygen Tension and Percentage of Oxygen Saturation in Patients with Polycythemia Vera

The curve (solid line) drawn through the plotted points connects mean values of oxygen saturation at corresponding oxygen tensions for normal adults (8). The probable area of normal variation is included between the broken lines which connect points which are \pm two standard deviations from the mean.

polycythemia vera differs from the normal. Unfortunately the number of cases is comparatively small but includes three with arterial saturation below the normal limit.

In contrast to the polycythemic blood in cyanotic congenital heart disease, there is little evidence of abnormality in the acid-base equilibrium of the blood in patients with polycythemia vera. The few abnormalities that are apparent in Table III appear to be isolated and not characteristic of the group as a whole. In general, carbon dioxide content and combining power of the blood tend to be lower than normal. This can be attributed to the greater percentage of cells in polycythemic blood since the carbon dioxide concentration is lower in red cells than it is in the plasma. In contrast to whole blood, the carbon dioxide combining power of the plasma is within the normal range in all except four cases. In 3 patients the arterial carbon dioxide tension appears lower than normal and in 2 instances higher. The $\mathrm{pH}_{\mathrm{s}}$ is slightly below the lower limit of normal in 3 patients.

\section{DISCUSSION}

In the absence of specific diagnostic criteria, polycythemia vera frequently is a diagnosis by exclusion of known causes of polycythemia. In addition to polycythemia related to congenital heart disease and pulmonary disease, abnormal blood pigments may contribute to the production of cyanosis and polycythemia. Methemoglobin may change to oxyhemoglobin during equilibration with oxygen in the determination of hemoglobin capacity. Since the oxygen content has not changed, the saturation may be low. Direct spectrophotometric analysis for methemoglobin was not done in the patients studied, but none had received any medication contributing to methemoglobin formation. The position of the oxygen dissociation curves within the normal range of adults offers indirect evidence for the absence of methemoglobin, since Darling and Roughton (14) have shown that in mixtures of methemoglobin and hemoglobin the oxygen dissociation curve is shifted to the left. The curve of D. J. who had arterial saturations as low as 79 per cent lay farther to the right than that of any of the polycythemia patients studied.

The statement is frequently made that the resting arterial saturation is normal in polycythemia vera in contrast to a lower saturation in secondary polycythemia. This conclusion has been affirmed by Moschcowitz (15), Hitzenberger (16), Brooks (17), Mohr (18), Röver (19), and more recently by Wasserman, Dobson, and Lawrence (20), who state that there is no great deficiency in the saturation of the circulating hemoglobin with oxygen. However, more recently Newman, Feltman, and Devlin (21) reported low saturation in 2 of 5 patients studied.

The data of Table I are also at variance with the commonly accepted belief that while arterial saturation in polycythemia vera tends to fall in the lower range of normal, it is within the normal range. The few low saturations which have been reported have been explained on the basis of probable pulmonary complications. Although a few of the patients included in the study may possibly have had complicating abnormalities of pulmonary origin, these could not be identified by clinical or $x$-ray examination, except in one instance where there was scoliosis, and pulmonary hemorrhages at the height of polycythemia. In the case of J. P., 14 years old, who had an arterial saturation of 80.5 per cent the diagnosis of polycythemia vera was confirmed by autopsy 3 years subsequent to the blood studies, when she died from a brain abscess. If normal arterial oxygen saturation is a required criterion for the diagnosis of polycythemia vera, 
a number of polycythemias of unknown origin that have diminished arterial oxygen saturation will remain.

In our data the lower than normal saturations are not associated with the higher oxyhemoglobin capacities. On the other hand, of the 4 cases with the most marked polycythemia, with oxyhemoglobin capacities of 31.1 to 34.4 volumes per cent, only one had a slightly reduced saturation of 92.6 per cent and the others were well within the normal range. The high viscosity of the blood in polycythemia does not in itself prevent normal saturation of the blood with oxygen as it passes through the pulmonary capillaries.

The same variability and lack of correlation between polycythemia and arterial unsaturation is seen, in a converse sense, in cyanotic congenital heart disease. Many infants are seen with arterial saturations of 50 to 80 per cent, but with hemoglobin concentrations as low as 10 gms. per 100 $\mathrm{ml}$. Older children with cyanotic congenital heart disease may not necessarily have a compensatory polycythemia.

The results with oxygen breathing prove that any arterial unsaturation observed while the patient with polycythemia is breathing air cannot be attributed to a venous admixture greater than may occur in normal persons. This would almost certainly place the source of the unsaturation in the lungs, either in poorly ventilated areas which are perfused with blood, or in a change in the alveolar membrane which impairs diffusion of oxygen from the alveoli to the blood. Reports in the literature suggest that both of these sources of unsaturation are possible. Harrop and Heath (22) found that the rate of diffusion of carbon monoxide across the alveolar walls is lower in patients with polycythemia vera than in normal persons, and that patients who have normal arterial saturation at rest may have this saturation reduced when they engage in exercise. Newman, Feltman, and Devlin (21) suggest that impariment to diffusion may be caused by thromboses in the alveolar capillaries. They believe, however, that arterial unsaturation in polycythemia vera may also be caused by other pulmonary changes. They present evidence of impaired lung ventilation which they attribute both to damage to the respiratory centers and to a decrease in the elasticity of the lung tissue and an increase in its viscous resistance to changes in shape due to the increased viscosity of the blood. Such changes, they believe, may lead to arterial unsaturation by perfusion of poorly ventilated lung areas.

Bansi and Groscurth (23) found a displacement of the oxyhemoglobin dissociation curve to the left in the blood of one of three patients with polycythemia vera. They interpreted this displacement as a compensation to maintain the oxygen tension in the tissues at a normal level in the presence of increased hemoglobin in the blood. It is difficult to reconcile their findings with the results shown in Figure 1. The possibility of a $\mathrm{pH}$ effect should be considered. Bansi and Groscurth made no correction to a constant $\mathrm{pH}$, while in the dissociation curves reported here the results of all equilibrations were corrected to a $\mathrm{pH}_{\mathrm{c}}$ of 7.1 by methods described by Keys, Hall and Barron (7). Richards and Strauss (24) in a study of the oxygen dissociation curve in anemia included one case of polycythemia vera. The dissociation curve was normal.

In an earlier report (1) evidence was presented that in the polycythemia secondary to congenital heart disease the oxygen dissociation curve of the blood tends to be displaced to the right, this displacement being more pronounced in patients in whom blood flow to the lungs was reduced by congenital pulmonary stenosis. The essentially normal oxyhemoglobin curve of the blood of patients with polycythemia vera shows that the displacement of the curve in cyanotic congenital heart disease is not caused by polycythemia itself. The results seem to show that while the hemoglobin in the blood of polycythemia vera is normal in respect to its oxygen binding and dissociation characteristics the hemoglobin in the blood of polycythemic patients with cyanotic congenital heart disease is abnormal in these respects. While the number of patients studied was inadequate to substantiate this finding, the results suggest that this difference may prove useful in differentiating these types of polycythemia. It is not yet clear in which category of oxygen dissociation curve the polycythemia secondary to pulmonary disease will fall.

\section{SUMMARY AND CONCLUSIONS}

The oxygen capacity, the oxygen saturation and the acid-base properties of arterial blood were 
studied in 17 patients with polycythemia vera. The results have been compared with the normal and with patients with polycythemia secondary to congenital heart disease. The arterial blood of five patients with polycythemia vera was studied before and after reduction of polycythemia by therapy. The effect of breathing pure oxygen upon the arterial saturation was determined in nine cases of polycythemia vera, and the oxygen dissociation curve was determined in eight patients. The results of these studies show:

1. Seven of the 17 patients in the study were found to have arterial saturations below the lower limit of normal, and in three patients the saturation was unquestionably low.

2. The finding of normal arterial saturation in some patients with polycythemia vera, including those with the highest hemoglobin, leads to the conclusion that polycythemia itself is not the cause of the arterial unsaturation. This conclusion is also supported by the variable effects of therapy upon the arterial saturation.

3. The observation that breathing oxygen raises the oxygen content of arterial blood to a degree comparable to that observed in normal arterial blood eliminated venous admixture as a cause of arterial unsaturation in polycythemia vera and suggests a pulmonary origin of unsaturation although not necessarily of polycythemia.

4. The oxygen dissociation of the blood was found to be normal. This is in contrast to a shift of the dissociation curve to the right in polycythemia secondary to congenital heart disease and indicates that the latter effect is not due to polycythemia alone. The results suggest that this difference may prove to be an important diagnostic aid.

5. Except for a decrease of the carbon dioxide combining power of the blood due to the higher concentration of the red cells in polycythemia vera, other acid-base properties of the blood in this disease, including the carbon dioxide combining power of the plasma, usually resemble the normal. A few isolated exceptions do not appear to be characteristic of the disease.

\section{REFERENCES}

1. Morse, M., Cassels, D. E., and Holder, M., The position of the oxygen dissociation curve of the blood in cyanotic congenital heart disease. J. Clin. Invest., 1950, 29, 1098.
2. Morse, M., and Cassels, D. E., Arterial blood gases in congenital heart disease. To be published.

3. Talbot, J. H., Coombs, F. S., Castleman, B., Chamberlain, F. L., Consolazio, W. V., and White, P. D., A record case of Tetralogy of Fallot, with comments on metabolic and pathologic studies. Am. Heart J., 1941, 22, 754.

4. Suarez, J. R. E., Chiodi, H., Fasciolo, J. C., and Taquini, A. C., Respiration and circulation in Morbus Coeruleus. Acta Cardiologica, 1949, 4, 439.

5. Van Slyke, D. D., and Neill, J. M., The determination of gases in blood and other solutions by vacuum extraction and manometric measurement. I. J. Biol. Chem., 1924, 61, 523.

6. Dill, D. B., Graybiel, A., Hurtado, A., Taquini, A. C., Der Gasaustausch in den Lungen im Alter. Ztschr. f. Altersforschung, 1940, 2, 20.

7. Keys, A., Hall, F. G., and Barron, E. S. G., The position of the oxygen dissociation curve of human blood at high altitude. Am. J. Physiol., 1936, 115, 292.

8. Morse, M., Cassels, D. E., and Holder, M., The position of the oxygen dissociation curve of the blood in normal children and adults. J. Clin. Invest., 1950, 29, 1091.

9. Henderson, $Y$., and Haggard, $H$. W., The circulation and its measurement. Am. J. Physiol., 1925, 73, 193.

10. Dill, D. B., Edwards, H. T., and Consolazio, W. V., Blood as a physiochemical system. XI. Man at rest. J. Biol. Chem., 1937, 118, 635.

11. Wood, E. H., Normal oxygen saturation of arterial blood during inhalation of air and oxygen. J. Appl. Physiol., 1949, 1, 567.

12. Roughton, F. J. W., Darling, R. C., and Root, W. S., Factors affecting the determination of oxygen capacity, content and pressure in human arterial blood. Am. J. Physiol., 1944, 142, 708.

13. Sendroy, J., Jr., Dillon, R. T., and Van Slyke, D. D., Studies of gas and electrolyte equilibria in blood. XIX. The solubility and physical state of uncombined oxygen in blood. J. Biol. Chem., 1934, 105, 597.

14. Darling, R. C., and Roughton, F. J. W., The effect of methemoglobin on the equilibrium between oxygen and hemoglobin. Am. J. Physiol., 1942, 137, 56.

15. Moschcowitz, E., Essays on the Biology of Disease. Chapter 6, The biology of polycythemia vera. J. Mt. Sinai Hosp., 1944, 11, 232.

16. Hitzenberger, K., Die Sauerstoffsättigung des arteriellen Blutes bei Polycythämien. Ztschr. f. klin. Med., 1934, 126, 495.

17. Brooks, W. D. W., Circulatory adjustments in polycythaemia rubra vera. Proc. Roy. Soc. Med., 1936, 29, 1379.

18. Mohr : Zur Klinik der Polycythämie. München Med. Wchnschr., 1913, 60, 1739.

19. Röver, F., Ueber hyperglobulie. München Med. Wchnschr., 1911, 58, 2791. 
20. Wasserman, L. R., Dobson, R. L., and Lawrence, J. $\mathrm{H}$., Blood oxygen studies in patients with polycythemia and in normal subjects. J. Clin. Invest., $1949,28,60$.

21. Newman, W., Feltman, J. A., and Devlin, B., Pulmonary function studies in polycythemia vera. Results in five probable cases. Am. J. Med., 1951, 11, 706.

22. Harrop, G. A., Jr., and Heath, E. H., Pulmonary gas diffusion in polycythemia vera. J. Clin. Invest., 1927, 4, 53.

23. Bansi, H. W., and Groscurth, G., Veränderungen der Sauerstoffbundingskurven des Blutes bei Stoffwechsel-und Blutkrankheiten (Anämie und Polycythämie). Ztschr. f. klin. Med., 1930, 113, 560.

24. Richards, D. W., Jr., and Strauss, M. L., Oxy-hemoglobin dissociation curves of whole blood in anemia. J. Clin. Invest., 1927, 4, 105. 